\title{
A Case Report of Wellens' Syndrome: An Ominous Sign of Left Anterior Descending Artery Critical Stenosis and Impending Anterior Myocardial Infarction
}

\author{
Herick Alvenus Willim(1,2), Andini Agustyana,,3), Dwisetyo Gusti Arilaksono, ${ }^{1,4}$, \\ Nurnajmia Curie Proklamartina ${ }^{1,4)}$, Muhammad Furqon5)
}

\author{
1)Pupuk Kaltim Hospital, Bontang, East Kalimantan \\ 2)General Practitioner, Dr. Agoesdjam General Public Hospital, Ketapang, West Kalimantan \\ 3) General Practitioner, Siaga Al Munawwarah Hospital, Samarinda, East Kalimantan \\ 4)Department of Cardiology and Vascular Medicine, Faculty of Medicine Universitas Indonesia, Jakarta \\ 5)Department of Cardiology and Vascular Medicine, Abdul Wahab Sjahranie General Public Hospital, \\ Samarinda, East Kalimantan
}

\section{ABSTRACT}

Background: Wellens' syndrome is a potentially life-threatening condition, characterized by biphasic or deeply inverted T-waves changes in electrocardiographic (ECG) precordial leads, which associated with critical stenosis of left anterior descending (LAD) coronary artery and impending anterior myocardial infarction in patients presenting with unstable angina. This syndrome is an important sign for clinicians because delay in coronary angiography and revascularization may lead toanterior myocardial infarction, left ventricular dysfunction, and even death.

Case presentation: A 50-year-old woman came to emergency department in a hospital in Bontang, with new onset intermittent typical chest pain lasting since 3 days. She had history of hypertension without regular medication. Physical examination was in normal ranges. An ECG obtained during chest pain-free period showed Wellens' type A with biphasic $\mathrm{T}$ waves in $\mathrm{V} 2-\mathrm{V} 6$ and preserved $\mathrm{R}$-wave progression. Troponin T was slightly elevated. During observation, the ECG pattern changed from Wellens' type A to Wellens' type B with deep T-wave inversions in $\mathrm{V} 2-\mathrm{V} 6$ and preserved $\mathrm{R}$-wave progression.

Cite this as:

Willim HA, Agustyana A, Arilaksono DG, Proklamartina NC, Furqon M (2020). A Case Report of Wellens' Syndrome: An Ominous Sign of Left Anterior Descending Artery Critical Stenosis and Impending Anterior Myocardial Infarction. Indones J Med. 05(03): 246-252. https://doi.org/10.26911/theijmed.2020.05.03.10.

cC (i) I Indonesian Journal of Medicine is licensed under a Creative Commons

cc) $\mathrm{EY}$ NC SA Attribution-NonCommercial-ShareAlike 4.o International License.

\section{BACKGROUND}

Wellens' syndrome is a specific electrocardiographic (ECG) abnormalities in pre-
Results: The patient was initially treated with conservative treatment. On the next day, she was referred to percutaneous coronary intervention-capable hospital in Samarinda. Coronary angiography revealed 90\% stenosis of mid LAD. A drug-eluting stent was successfully implanted with restoration of LAD flow. She was discharged on the following day in good condition with medication of dual antiplatelet therapy, angiotensin-converting enzyme inhibitor, beta-blocker, and statin.

Conclusion: Clinicians should be aware of the ECG changes in Wellens' syndrome, which may occur during pain-free period. Early recognition is crucial to avoid the development of anterior myocardial infarction. Immediate coronary angiography and revascularization is needed.

Keywords: Wellens' syndrome, critical stenosis, myocardial infarction

\section{Correspondence:}

Herick Alvenus Willim. Dr. Agoesdjam General Public Hospital, Ketapang, West Kalimantan. Email: herick_alvenus@yahoo.co.id. cordial $\mathrm{T}$ waves, which reflects the preinfarction stage of significant left anterior descending (LAD) coronary artery stenosis 
(Kyaw et al., 2018). Wellens' syndrome also known as LAD coronary syndrome or widow maker sign (Al-assaf et al., 2019). This ECG phenomenon was first described by De Zwaan et al.(1982) in the subgroup of patients with unstable angina, which associated with a critical stenosis of the LAD. Two different ECG pattern of Wellens' syndrome have been described. Type A presents with biphasic $\mathrm{T}$ waves and type $\mathrm{B}$ presents with symmetrical deep $\mathrm{T}$-wave inversions in precordial leads, especially seen in V2-V3 (Mufti et al., 2018).

Recognition of Wellens' syndrome is important because the patients may develop an extensive acute anterior myocardial infarction within a few days and the risk of sudden cardiac arrest is high (Karadzic et al., 2012). The T-wave changes in Wellens' syndrome are typically observed in patients with unstable angina during a pain-free period. Although these patients may firstly respond well to medical management, they eventually respond poorly with conservative treatment and require immediate revascularization therapy (Wang et al., 2018). Here, we present a case of a 50-year-old woman with diagnosed with Wellens' syndrome, which was proven to have critical stenosis in LAD.

\section{CASE PRESENTATION}

A 50-year-old woman came to emergency department (ED) in a hospital in Bontang, East Kalimantan with new onset intermittent chest pain lasting since 3 days. The chest pain was felt like heaviness in left chest, radiating to shoulder and left arm, associated with dyspnea and diaphoresis, persisting up to 30 minutes and relieving spontaneously. The occurrence were associated with exertion. She had not experienced such pain in the past. She had history of hypertension without regular medication. History of smoking, diabetes mellitus, and dyslipidemia was denied.

On physical examination, she was in chest pain-free and no distress condition. She was alert and fully oriented. Heart rate was 76 beats/min, blood pressure was $160 / 100 \mathrm{mmHg}$, respiratory rate was 18 breaths/min, body temperature was $36.6^{\circ} \mathrm{C}$, and oxygen saturation was $98 \%$ on room air. Neck examination revealed no jugular venous distention. Cardiac examination revealed no murmurs or gallops. Lung examination revealed no rales or wheezing. Abdominal and extremity examination was normal.

An ECG obtained in chest pain-free condition showed biphasic $\mathrm{T}$ waves in V2V6 with preservedR-wave progression, which is typical for Wellens' type A (Figure 1). Troponin $\mathrm{T}$ was slightly elevated at 0.05 $\mu \mathrm{g} / \mathrm{L}$ (normal reference <0.014 $\mu \mathrm{g} / \mathrm{L}$ ). Chest radiograph revealed no abnormalities. Laboratory tests including complete blood count, liver function, renal function,lipid profile, and blood glucose were normal. She was diagnosed with Wellens' syndrome and given aspirin $160 \mathrm{mg}$ and clopidogrel $300 \mathrm{mg}$. Serial ECG evaluation after 1 hour showed deep T-waves inversion in V2-V6 with preserved R-wave progression, which is typical for Wellens' type $\mathrm{B}$ (Figure 2).

Our ED team explained to the patient and her family that the patient needed to be referred to percutaneous coronary intervention (PCI)-capable hospital in Samarinda, East Kalimantan for coronary angiography and possibly requiring revascularization therapy, but they said that they still wantto discuss whether they will proceed with our treatment plan. While waiting for the patient and family's decision, the patient was treated in intensive care unit with conservative treatment of acute coronary syndrome, including enoxaparin $40 \mathrm{mg}$ 
twice daily, aspirin $80 \mathrm{mg}$ once daily, clopidogrel $75 \mathrm{mg}$ once daily, captopril 25 $\mathrm{mg}$ three times daily, bisoprolol $2.5 \mathrm{mg}$ once daily, and atorvastatin $40 \mathrm{mg}$ once daily.

On the next day, serial ECG was still showed Wellens' syndrome type B. The patient and her family finally agreed to be referred to PCI-capable hospital in Sama- rinda. Coronary angiography revealed 90\% stenosis of the mid LAD. She underwent successful PCI with drug-eluting stent (Figure 3). She was discharged on the following day in a good condition and advised to continue dual antiplatelet therapy for 1 year along with other medications including angiotensin-converting enzyme inhibitor, beta-blocker, and statin.

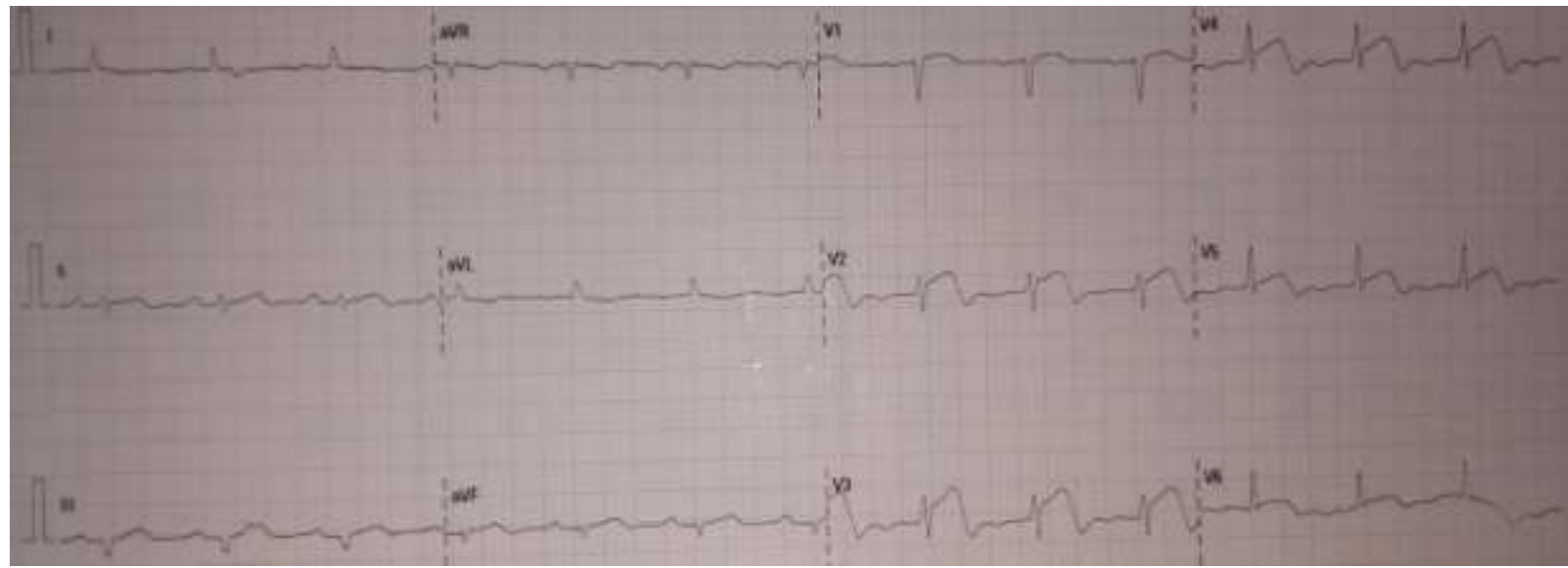

Figure 1. Initial ECG showing sinus rhythm with biphasic $T$ waves in V2-V6 and preserved R-wave progression (Wellens' syndrome type A)

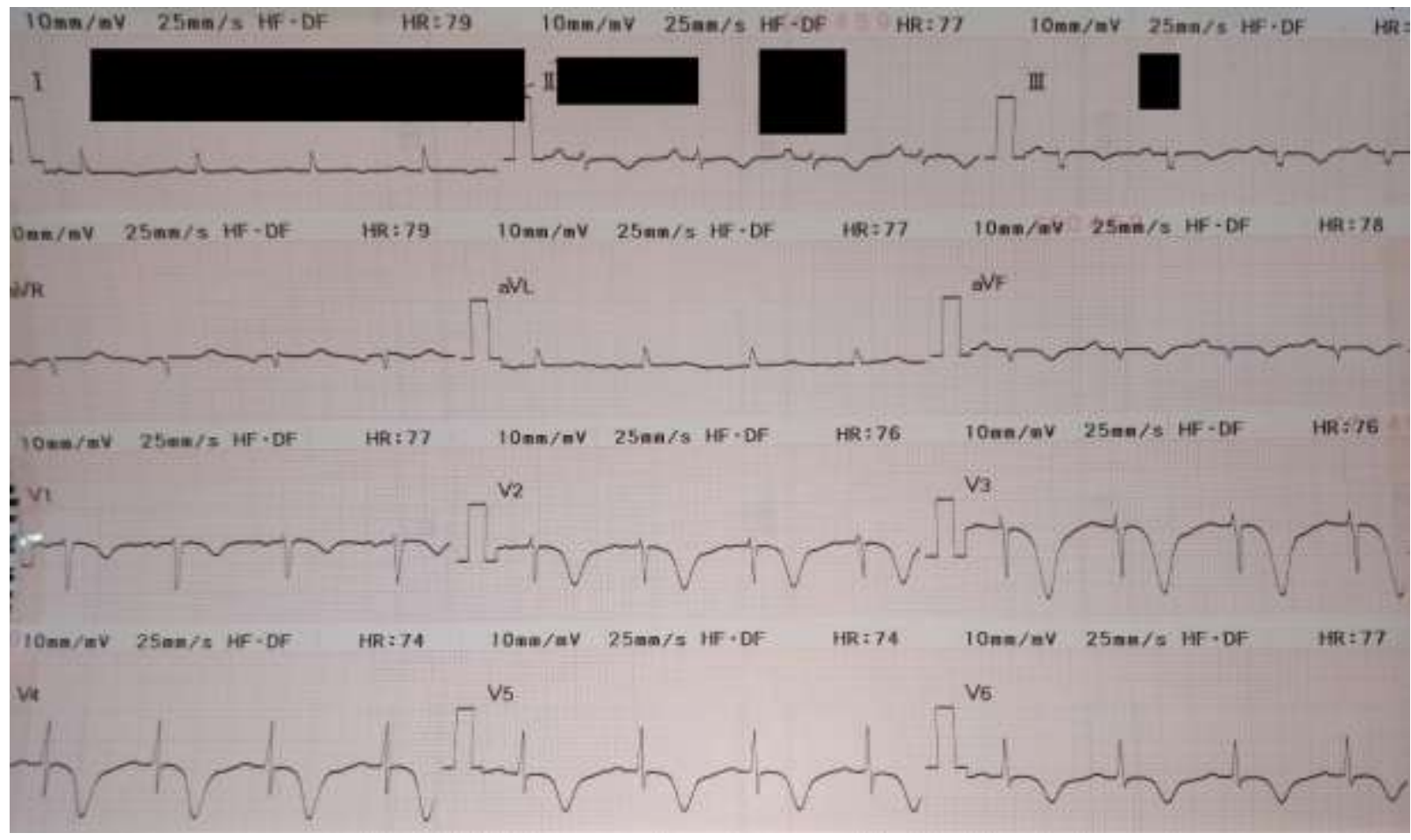

Figure 2. Serial ECG after 1 hour showing sinus rhythm with deep T-wave inversions in V2-V6 and preserved $R$-wave progression

(Wellens' syndrome type B) 


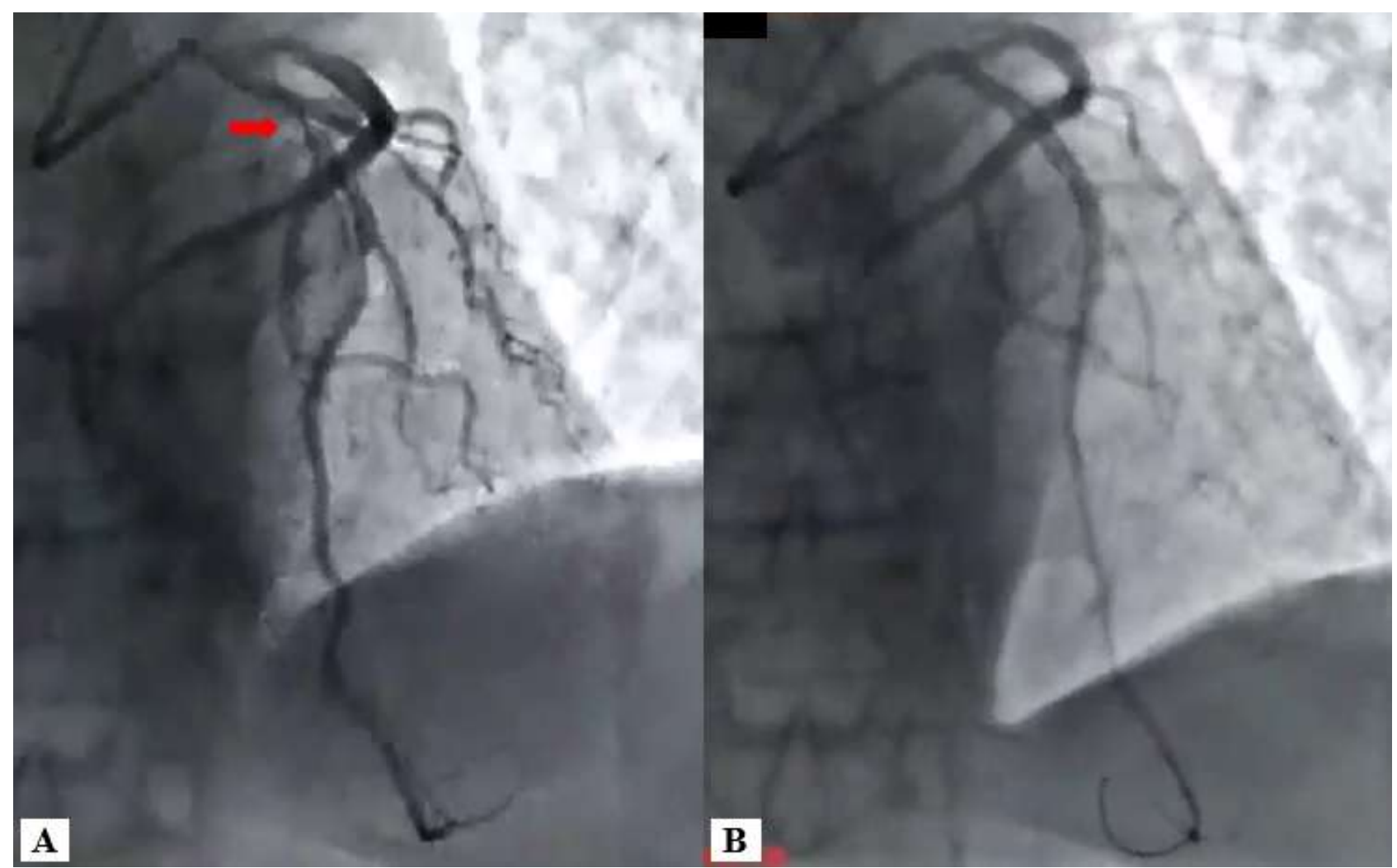

Figure 3. Coronary angiography showing $90 \%$ stenosis (red arrowhead) in the mid LAD (A), drug-eluting stent was successfully implanted with restoration of the LAD flow (B)

\section{DISCUSSION}

This case report shows the typical ECG findings of Wellens syndrome in a 50-year old woman with intermittent typical chest pain and history of hypertension. Wellens' syndrome is typically described by ECG Twave changes in precordial leads implicating critical stenosis of the LAD (Cruz et al., 2017). The incidence is approximately $10-15 \%$ of patients with acute coronary syndrome(Ooet al., 2016). The diagnostic criteria of Wellens' syndrome include: previous history of angina, minimal or no elevation of cardiac enzymes, minimal or no ST-segment elevation, no loss of precordial R-wave progression, no pathologic precordial Q waves, and biphasic or deep Twave inversions in leads $\mathrm{V}_{2}$ and $\mathrm{V}_{3}$, sometimes also found in $\mathrm{V}_{1}, \mathrm{~V}_{4}, \mathrm{~V}_{5}$, and V6(Cruz et al., 2017). The patient in this case fulfilled all diagnostic criteria of Wellens' syndrome.

There are two different patterns of precordial T-wave changes seen in Wellens' syndrome. Wellens' type A was found in $25 \%$ of cases has biphasic $\mathrm{T}$ waves with initial positivity and terminal negativity. Wellens' type B was found in $75 \%$ of cases has deep symmetrical T-wave inversions (Mufti et al., 2018). The T wave changes can occur over time from type A to type B, which occurred in this patient while she was in the ED.

The T-wave changes in Wellens' syndrome typically occur during a chest pain-free interval as happened in this case when the first ECG was recorded. It reflect the state of stunning and reperfusion of the myocardium. Total or near-total occlusion of LAD causes myocardial ischemia and chest pain. Once coronary artery flow is 
restored, reperfusion injury related repolarization abnormalities will be seen in precordial leads with biphasic or T-wave inversions (Abulaiti et al., 2013).

Wellens' syndrome classically indicate the presence of critical stenosis in LAD, particularly the proximal part of LAD (Ramires et al., 2018). A study conducted byBandara et al.(2018)of 30 patients with Wellens' syndrome found that majority 70\% (22 patients) had proximal LAD critical stenosis, which was marked by $\geq 90 \%$ luminal stenosis.In our case, the critical stenosis was found to be in the mid rather than the proximal part of LAD. Kardesoglu et al.(2003) reported similar finding in a Wellens' syndrome patient, where the critical stenosis was found in mid LAD. Pallangyo et al. (2020)also reported similar finding where the critical stenosis was found in mid LAD. These findings suggest that Wellens' syndrome may not only be a marker of proximal LAD critical stenosis, but also could be a sign of mid LAD critical stenosis as happened in our case.

Recognition of Wellens' syndrome is important because this syndrome reflects a preinfarction stage of coronary artery disease. Since the LAD supplies anterior myocardium, failure to recognize this syndrome may cause delay in sending the patients to immediate coronary angiography and revascularization therapy which may lead to anterior myocardial infarction, significant left ventricular dysfunction, and even death. About $75 \%$ of patients with Wellens' syndrome who are only treated by conservative treatment and not revascularized will have extensive anterior myocardial infarction within few days, with a mean of 8.5 days from the onset (Singh et al., 2013).

Initial treatment principle of Wellens' syndrome is generally the same as acute coronary syndrome. Antiplatelet, anticoagulant and antianginal medications should be administered. After initial treatment, the patients should be transferred for immediate coronary angiography and revascularization therapy, either by PCI or coronary artery bypass grafting (Purwaningtyas et al., 2017). These patients should not undergo exercise stress test. Provocation of ischemiain these patients during stress test may result in adverse events such as acute myocardial infarction, serious arrhythmia and death (Arisha et al., 2019).

This case study concludes that clinicians should be aware of the ECG changes in Wellens' syndrome, which may occur during pain-free period. Early recognition of it is crucial because the patients are at high risk for impending anterior myocardial infarction. These patients require invasive therapy, do poorly with conservative treatment. Once Wellens' syndrome has been diagnosed, immediate coronary angiography and revascularization therapy should be performed at the earliest time.

\section{AUTHOR CONTRIBUTION}

All of the authors contributed equally and agreed to the final manuscript. Herick Alvenus Willim and Andini Agustyana wrote the manuscript with input from all authors. Dwisetyo Gusti Arilaksono and Nurnajmia Curie Proklamartina performed the patient's treatment in Pupuk Kaltim Hospital and revised the manuscript. Muhammad Furqon performed the percutaneous coronary intervention in Abdul Wahab Sjahranie General Public Hospital.

\section{CONFLICT OF INTEREST}

The authors declare that there is no conflict of interest regarding the publication of this article. 


\section{FUNDING AND SPONSORSHIP}

The authors received no funding for the publication of this article.

\section{ACKNOWLEDGEMENT}

We would like to thank to Pupuk Kaltim Hospital and Abdul Wahab Sjahranie General Public Hospital for the help and permission in data collection of this case. An abstract of this paper was previously presented at the Jogja Cardiology Update 2019 in Jogjakarta, Indonesia on Juli 19, 2019 as a moderated poster.

\section{REFERENCE}

Abulaiti A, Aini R, Xu H, Song Z (2013). A special case of Wellens' syndrome.J Cardiovasc Dis Res, 4(1): 51-54. doi: 10.1016/j.jcdr.2013.02.016.

Al-assaf O, Abdulghani M, Musa A, AlJallaf M (2019). Wellens' syndrome: the life-threatening diagnosis.Circulation, 140:1851-1852. doi: 10.1161/CIRCULATIONAHA.119.043780.

Arisha MJ, Hallak A, Khan A (2019). A rare presentation of a rare entity: Wellens' syndrome with subtle terminal T wave changes. Case Rep Emerg Med, 2019: 1582030. doi: 10.1155/2019/1582030.

Bandara HGWAPL, Weerakoon WMG, Jegavanthan A, Jayasekara NMTC, Kogulan T, Kularatne A, Sirisena TS, et al. (2018). Echocardiographic and angiographic characteristics of patients with Wellens' syndrome who underwent percutaneous coronary interventions. Int $\mathrm{J}$ Recent Sci Res, 9(6): 27655-27659. doi: 10.24327/IJRSR.

Cruz MC, Luiz I, Ferreira L, Ferreira RC (2017). Wellens' syndrome: A bad omen. Cardiology, 137(2): 100-103. doi: 10.1159/000455911.

De Zwaan C, Bar FW, Wellens HJ (1982). Characteristic electrocardiographic pattern indicating a critical stenosis high in left anterior descending coronary artery in patients admitted because of impending myocardial infarction. Am Heart J. 103: 730-736. doi: 10.1016/0002-8703(82)90480-x

Karadzic M, Vuckovic-Filipovic J, Davidovic G, Iric-Cupic V, Tasic MP, Kovacevic $Z$ (2012). The "widow maker" warning sign or wellens' syndrome: a case report.Arch Bio l Sci, 64(2):733738. d oi: 10.2298/ABS1202733K

Kardesoglu E, Celik T, Cebeci BS, Cingozbay BY, Dincturk M, Demiralp E (2003). Wellens' syndrome: a case report.J Int Med Res, 31:585-590. doi: 10.1177/147323000303100615.

Kyaw K, Latt H, Aung SSM, Tun NM, Phoo WY, Yin HH (2018). Atypical presentation of acute coronary syndrome and importance of Wellens' syndrome.Am J Case Rep, 19: 199-202. doi: 10.12659/AJCR.907992.

Mufti M, Joea R, Sobnosky S, Longtine J (2018). Wellens' Syndrome: an atypical presentation of an already silent killer. J Med Cases, 9(6):173-176. doi: 10.14740/jmc3058e.

Oo SZMWH, Khalighi K, Kodali A, May C, Aung TT, Snyder R (2016). Omnious T-wave inversions: Wellens' syndrome revisited. J Community Hosp Intern Med Perspect, 6(4): 32011. doi: 10.3402/jchimp.v6.32011.

Pallangyo P, Bhalia S, Longopa G, Mwinyipembe K, Millinga J, Misidai N, Swai HJ, et al. (2020). A case of Wellens syndrome in a 30-year-old woman from Sub-Saharan Africa: a perplexing clinical entity with invaluable lessons. J Investig Med High Impact Case Rep, 8: 1-6. doi: 10.1177/2324709620918552.

Purwaningtyas N, Meriedlona N (2017). Wellens' syndrome and impending 
Willim et al./ A Case Report of Wellens' Syndrome

anterior wall myocardial infarction: a case report.Med Rep Case Stud, 2(3). doi: 10.4172/2572-5130.1000145.

Ramires TG, Sant'Anna J, Pais J, Picarra BC (2018). Wellens' syndrome: a pattern to remember.BMJ Case Rep. 2018: bcr2018224582. doi: 10.1136/bcr-2018-224582.

Singh B, Singh Y, Singla V, Nanjappa MC (2013). Wellens' syndrome: a classical

electrocardiographic sign of impending myocardial infarction. BMJ Case Rep, 2013:bcr2012008513. doi: 10.1136/bcr-2012-008513.

Wang X, Sun J, Feng Z, Gao Y, Sun C, Li G (2018). Two case reports of Wellens' syndrome. J Int Med Res, 46(11): 4845-4851. doi: 10.1177/0300060518800857 . 